ТКАЧЕНКО

Сергій Анатолійович tkachenko26091980@gmail.com

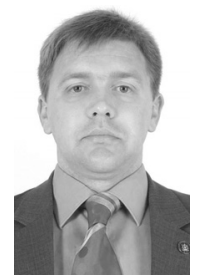

д.е.н., дочент, ректор, ВНЗ «Міжнародний технологічний університет «Миколаӥвська політехніка»
ТКАЧЕНКО

В 'ячеслав Анатолійович grandlist1986@gmail.com

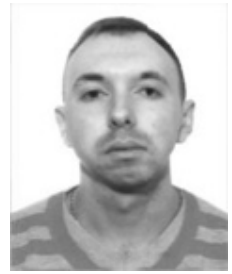

викладач, «Міжнародний технологічний університет «Миколаївська політехніка»
ТКАЧЕНКО

Світлана Вікторівна desvetlana66@gmail.com

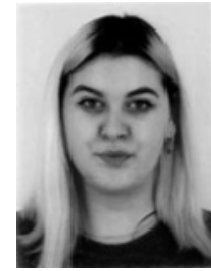

викладач, «Міжнародний технологічний університет «Миколаївська політехніка»

УДК 657

\title{
EMPHASIS IN FUNCTIONALLY DEVELOPED SYSTEMS OF STRATEGIC MANAGEMENT OF SPECIAL PURPOSE BY ENTERPRISES AND ASSOCIATIONS OF AN INDEPENDENT SUBSYSTEM OF INTEGRATED ECONOMIC ANALYSIS (EVALUATION)
}

TKACHENKO Serhii Anatoliiovych - Doctor of Economics, Associate Professor, Rector, Higher Educational Institution «International Technology University "Mykolaiv Polytechnic"»

TKACHENKO Viacheslav Anatoliiovych - lecturer, Higher Educational Institution «International Technology University "Mykolaiv Polytechnic"»)

TKACHENKO Svitlana Viktorivna - lecturer, Higher Educational Institution «International Technology University "Mykolaiv Polytechnic"»"

Аргументировано, что в условиях систем управления предприятиями каждый из видов подсистемы аналитической обработки экономических информационных данных можно представить в виде соответствующих блоков программ, реализующих совокупности последовательно связанных между собой аналитических альтернатив, образующих функииональную структуру планомерного экономического анализа и оценки. Обосновано, что в подсистеме аналитической обработки технико-экономических информачионных данных имеются структурные части, обладающие системными признаками, и следовательно, требование, заключающееся в выделении в системах управления предприятиями самостоятельной подсистемы монолитного экономического анализа (оченки), выполняется.

$$
* * *
$$

Дослідження функиій управління у умовах функціонально розвинутих систем стратегічного адміністрування спеціального призначення підприємствами промисловості та науково-виробничими об'єднаннями із позицій системного підходу надає підставу зробити висновок, щуо будь-яка частина системи управління організацією може бути визнана підсистемою, якщо відбувається дотримання наступної вимоги: у підсистемі можуть бути виділені частини, які мають систематичні ознаки і які зі свого боку можна назвати завданнями (комплексами задач) даної підсистеми управління. Розглянуто можливість виконання цієї однієї вимоги у умовах створення у функиіонально розвинених системах стратегічного адміністрування спеціального призначення промислових підприсмств та науково-виробничих об'єднань самостійної (автономної) функиіональної підсистеми (функції) аналітичної обробки техніко-економічних інформаційних даних (планомірного господарського аналізу і оцінки). В умовах функиіонально розвинених систем стратегічного управління спеціального призначення промисловими підприсмствами та науково-виробничими об'сднаннями кожен із видів підсистеми (функції) аналітичноі обробки техніко-економічних інформачійних даних можна представити у вигляді відповідних блоків програм, які реалізують сукупності послідовно пов'язаних між собою господарсько-аналітичних завдань, які утворюють функиіональну конфігурацію інтегрованого економічного аналізу та оцінки. Це дозволяє зробити висновок, що у підсистемі аналітичної обробки техніко-економічних інформаційних даних є структурні частини, які володіють системними ознаками, а отже, запит, який полягає у виділенні у функціонально розвинутих системах (методах) стратегічного управління спеціального призначення промисловими підприємствами та науково-виробничими об'єднаннями самостійної функиї иілісного економічного аналізу й оцінки, виконується.

$* * *$

The study of management functions in the conditions of functionally developed systems of strategic administration of special purpose by industrial enterprises and scientific-industrial associations from the standpoint of the systematic approach gives the reason to conclude that any part of the organizational management system can be recognized by the subsystem if the following requirement is fulfilled: $y$ subsystems can be allocated parts that have systematic features and which in turn can be called tasks 
(complexes of tasks) of a given subsystem emu management. The possibility of fulfilling this one requirement in the conditions of creation in the functionally developed systems of strategic administration of the special purpose of industrial enterprises and scientific-industrial associations of an independent (autonomous) functional subsystem (function) of analytical processing of technical and economic information data (systematic economic analysis and evaluation) is considered. In the conditions of functionally developed systems of strategic management of special purpose by industrial enterprises and scientific-industrial associations, each of the types of subsystem (function) of analytical processing of technical and economic information data can be represented in the form of corresponding blocks of programs that implement sets of sequentially interconnected economically Analytical tasks that form the functional configuration of integrated economic analysis and evaluation. This leads to the conclusion that in the subsystem of analytical processing of technical and economic information data there are structural parts, which undoubtedly possess system features, and, consequently, a requirement which consists in isolation in the functionally developed systems (methods) of strategic management of special purpose by industrial enterprises and scientific-production associations of the independent function of integrated economic analysis and evaluation are also performed.

Ключевые слова: выделение, интегрированный экономический анализ и оченка, самостоятельная подсистема, система стратегического контроля, специфическое назначение, учреждение, функционально развитой и функция

Ключові слова: виокремлення, інтегрований економічний аналіз і оиінка, об єднання, підприємство, самостійна підсистема, система стратегічного управління, специффічне призначення, функціонально розвинутий, функція, изіль

Keywords: function, functionally developed, independent subsystem, industrial enterprise, integrated economic analysis and evaluation, isolation, production association,special target, target and the strategic management system

\section{ВСТУПЛЕНИЕ}

Рассмотрим общесистемную предпосылку создания в функционально развитых систем стратегического управления специального назначения промышленными предприятиями и научно-производственными объединениями самостоятельной функциональной подсистемы (функции) аналитической обработки техникоэкономических информационных данных (интегрированного экономического анализа и оценки), уровень исследования которой представляется нам явно недостаточным. Требование отражения системного аспекта - системности в подходе к созданию такой подсистемы - вытекает из организационных, информационнотехнологических и временных взаимосвязей аналитических задач, объединяемых в самостоятельную подсистему, между собой, а также с задачами других подсистем функционально развитых систем стратегического управления специального назначения промышленными предприятиями и научно-производственными объединениями. Каждая задача функции планомерного экономического анализа и оценки занимает вполне определенное место не только в данной подсистеме, но и в системе управления в целом, поэтому оптимальность функционирования как самой подсистемы аналитической обработки технико-экономических информационных данных, так и всей функционально развитой системы стратегического управления специального назначения промышленным предприятием и научно-производственным объединением требует вполне чёткого и однозначного определения последовательности решения задач анализа (одна относительно другой и относительно других задач системы управления) в соответствующих производственных ситуациях. То есть основным условием рационального проектирования подсистемы аналитической обработки технико-экономических информационных данных является обеспечение системного подхода, при котором функция интегрированного экономического анализа и оценки рассматривается одновременно и как самостоятельный элемент управления, и как органическая часть системы управления в целом. Кроме того, системный подход предполагает, что подсистема (функция) аналитической обработки технико-экономических информационных данных (интегрированного экономического анализа и оценки) функционально развитых систем стратегического управления специального назначения промышленными предприятиями и научно-производственными объединениями должна быть совместима по методам и средствам обработки данных с вышестоящими системами управления, в частности с объединёнными функционально развитыми системами стратегического управления специального назначения. Однако системный подход не должен сводиться к учёту исключительно только информационных факторов. Из-за различных технических, организационных и финансовых ограничений формирование подсистемы и пути её создания в функционально развитых системах стратегического управления специального назначения предприятиями промышленности и производственными объединениями в практических условиях могут иметь разнообразное целевое воплощение и др.

Исследование функций управления в условиях функционально развитых систем стратегического управления специального назначения предприятиями промышленности и научно-производственными объединениями с позиций системного подхода [1] даёт основание заключить, что любая часть системы управления организацией может быть признана подсистемой, если выполняется следующее требование: в подсистеме могут быть выделены части, которые обладают системными признаками и которые в свою очередь можно назвать задачами(комплексами задач) данной подсистемы управления.

\section{ЦЕЛЬ РАБОТЫ}

Рассмотрим возможность выполнения этого ключевого требования в условиях создания в функционально развитых системах стратегического управления специального назначения промышленных предприятий и научно-производственных объединений самостоятельной (активной) функциональной подсистемы (функции) аналитической обработки технико-экономических информационных данных (планомерного хозяйственного анализа, оценки). 


\section{МЕТОДЫ ИССЛЕДОВАНИЯ}

Теоретико-методологической основой данной научной статьи выступает диалектический метод, узловые позиции теории анализа, оценки, управления. В процессе освидетельствования использовались методы: абстрактно-логический (для философского обобщения и формулирования результатов); монографический (при трактовке резонных метод анализа, контроля, оценки).

\section{РЕЗУЛЬТАТЫ}

Современный уровень развития методологии подсистемы (функции) аналитической обработки техникоэкономических информационных данных (интегрированного экономического анализа и оценки) позволяет чётко выделить в ней составные части, представляющие отдельные виды анализа - оперативный (эффективный), перспективный, проблемно-ориентированный, ретроспективный (текущий), сравнительный, функционально-стоимостной. Между названными видами подсистемы (функции) аналитической обработки технико-экономических информационных данных (интегрированного экономического анализа и оценки) имеется определенное теоретико-методологическое единство, обусловленное единым объектом исследования и использования в целом ряде случаев единой информационной базы и одинаковых способов и приёмов получения тех или иных экономико-аналитических показателей и критериев оценки эффективности (качества), а также существуют информационно-логические и временные связи. Хотя каждый из видов подсистемы (функции) аналитической обработки технико-экономических информационных данных имеет свою определенную цель, тем не менее, каждый из них, действуя на промышленных предприятиях и в научно-производственных объединениях в рамках системы планомерного экономического анализа и оценки, подчинён общей её генеральной цели.

В условиях функционально развитых систем стратегического управления специального назначения предприятиями и объединениями каждый из видов подсистемы (функции) аналитической обработки техникоэкономических информационных данных можно представить в виде соответствующих блоков программ, реализующих совокупности последовательно связанных между собой экономико-аналитических задач, образующих функциональную структуру интегрированного экономического анализа и оценки. Это позволяет сделать вывод, что в подсистеме аналитической обработки технико-экономических информационных данных имеются структурные части, также обладающие системными признаками, и следовательно, запрос, заключающийся в выделении в функционально развитых системах (методах) стратегического управления специального назначения предприятиями и объединениями самостоятельной функции интегрированного экономического анализа (оценки), также выполняется.

Таким образом, как с точки зрения сущности управления современным научно-производственным объединением и промышленным предприятием - самостоятельности и значения функции интегрированного экономического анализа и оценки в управлении, так и с позиций системного подхода выделение в числе функциональных подсистем функционально развитых систем стратегического управления специального назначения промышленными предприятиями и научнопроизводственными объединениями самостоятельной подсистемы аналитической обработки технико-экономических информационных данных можно считать научно обоснованным и вполне правомерным. Исследование характера выполнения приведённого выше требования не только свидетельствует о наличии соответствующей теоретической предпосылки для выделения в функционально развитых системах стратегического управления специального назначения промышленными предприятиями и научно-производственными объединениями самостоятельной подсистемы (функции) аналитической обработки технико-экономических информационных данных (интегрированного экономического анализа и оценки), но и позволяет также сформулировать её целевое определение (дефиницию). В этой связи, на наш взгляд, под подсистемой (функцией) аналитической обработки техникоэкономических информационных данных (интегрированного экономического анализа и оценки) функционально развитой системы стратегического управления специального назначения предприятием и объединением можно понимать совокупность базирующихся на использовании новейших экономико-математических методов и современной вычислительной техники организационно-методологических средств, обеспечивающих возможность получения машинным электронным цифровым путём аналитических данных, так необходимых для объективной оценки хозяйственной деятельности, выявления оперативных, текущих, перспективных резервов повышения её качества, подготовки и обоснования управляющих решений по проблемам экономического, технического, организационного, социального характера.

Целесообразность формирования в проектируемых и действующих функционально развитых системах стратегического администрирования специального назначения предприятиями и объединениями подсистемы аналитической обработки технико-экономических информационных данных вытекает из необходимости переработки большого объема исходных данных, сложности и трудоёмкости экономико-аналитических расчётов, определяется постоянно возрастающими требованиями системы управления к функции интегрированного экономического анализа и оценки в направлении повышения её аналитичности и качества, комплексности и оперативности.

\section{ВЫВОДЫ}

Придерживаясь точки зрения о том, что наибольшие результаты от усовершенствования на предприятиях функции интегрированного экономического анализа и оценки могут быть достигнуты только при создании в функционально развитых системах стратегического управления специального назначения предприятиями и объединениями самостоятельной подсистемы аналитической обработки экономических информационных данных, можно отметить, что рассмотрение функции анализа с позиций системного подхода способно обеспечить определенный эффект 
и при других формах улучшения анализа, допускающих, в частности, рассредоточение экономико-аналитических задач по различным подсистемам функционально развитых систем стратегического управления специального назначения предприятиями (объединениями), когда анализ наряду с другими функциями управления выступает общим компонентом этих подсистем. Эффект в этих условиях будет обеспечиваться главным образом в результате того, что системный подход к подсистеме (функции) аналитической обработки экономических информационных данных (интегрированного экономического анализа и оценки), с одной стороны, облегчит выбор единых теоретико-методологических решений для экономикоаналитических задач разных подсистем, а с другой стороны позволит в соответствии с общим деревом целей функции анализа достичь более полной увязки и согласованности экономико-аналитических задач, решаемых в различных подсистемах функционально развитых систем стратегического управления специального назначения предприятиями и объединениями. Таким образом, даже при децентрализации в функционально развитых системах стратегического управления специального назначения промышленными предприятиями, производственными объединениями аналитических расчётов рассмотрение функции интегрированного экономического анализа и оценки, по крайней мере, на стадии технического проектирования, как единой монолитной подсистемы аналитической обработки технико-экономических информационных данных представляется необходимым, целесообразным.

\section{Список использованных источников}

1. Ткаченко С.А. Інтегрована економічна діагностика у функиіонально розвинутих системах стратегічного управління діяльністю підприємств та виробничих об'єднань: монографія. Харків: Смугаста типографія, 2017. 356 c.

\section{$\underline{\text { References }}$}

1. Tkachenko S.A. Integrated economic diagnostics in functionally developed systems of strategic management of the activity of enterprises and industrial associations: monograph. Kharkiv: Striped Typography,2017. 356 p. (in Ukrainian). 